\title{
Mail Box
}

\section{Corrections to First-Order Fuzzy Logic}

\section{Dear Editors,}

I found that the proof of the main theorem in my paper "First-Order Fuzzy Logic" which appeared in Studia Logica 46 (1987), pp. 88-109, contains a mistake. Unfortunately, the mistake had deeper roots and I had to change some concepts and prove new theorems. The completeness property of first-order fuzzy logic which I succeeded to prove concerns the language containing only universal and existential quantifiers (without the generalized ones) enriched by some additional connectives, if necessary.

New minimalised sets of logical axioms and rules of inference are defined. The notion of $\beta$-contradictoriness appeared to be useless since the theorem stating that there are either 1-contradictory or consistent theories has been proved. One of the most important new theorems is deduction one (in fuzzy sense) which is indispensable for the proof of completeness theorem.

The full version of the revised paper on first-order fuzzy logic containing all the proofs is available from the author upon the request sent on the address below.

I apologize to you and to all the readers.

Sincerely yours,

Vilém Novák

Czechoslovak Academy of Sciences

Mining Institute

Studentská 1768

70800 Ostrava-Poruba

Czechoslovakia 


\section{The Arthur Prior Memorial Conference}

On 18-23 August 1989 an international joint session of the Australasian Associations of Philosophy and Logic will be held to mark the twentieth anniversary of Prior's death. Papers are invited on Prior, his work, and the subjects on which he wrote (for example - tense logic, modal logic, ethics, determinism, intensionality, ontology, tome and change, self reference, indexicals, inferential definition, Aristotelian and medieval logic, logic and religion, epistemic, deontic and erotetic logics). The intention is to publish a selection of the conference proceedings in a Memorial Volume. The venue will be the University of Canterbury, New Zealand, where Prior held the Chair of Philosophy until 1958. Further details may be obtained from Jack Copeland, Philosophy Department, University of Cantenbury, Private Bag. Christchurch 1, New Zealand. 